Linköping Studies in Health Sciences, Thesis No. 134

\title{
Institutionally Shaped Response to the Introduction of National Guidelines \\ - Case Studies in the Swedish Regional Health Policy Arena
}

\author{
Johanna Sandberg
}

Department of Medical and Health Sciences

Linköping University, Sweden

Linköping 2018 
@ Johanna Sandberg, 2018

Published articles have been reprinted with the permission of the copyright holder.

Printed in Sweden by LiU-Tryck, Linköping, Sweden, 2018

ISBN 978-91-7685-225-5

ISSN 1100-6013 


\section{CONTENTS}

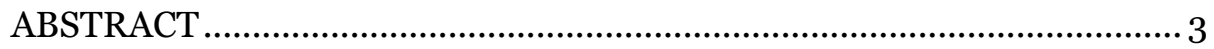

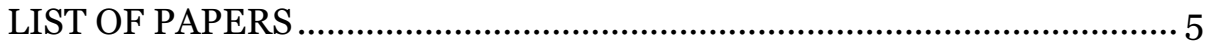

INTRODUCTION .................................................................................. 7

Evidence in policy................................................................................ 7

Management by knowledge ..................................................................... 8

Resource allocation and priority-setting ............................................... 10

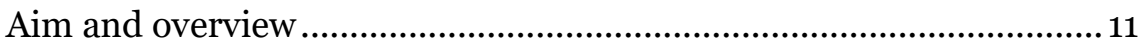

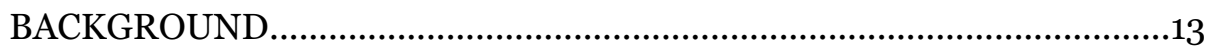

Theoretical framework ............................................................................13

Setting the scene - the Swedish health policy arena ............................15

Understanding a policy instrument - national guidelines ................... 16

METHODS AND MATERIAL .............................................................. 19

Choice of method - case studies........................................................ 19

Selection of cases and informants ........................................................20

Interviews and analysis ..................................................................... 22

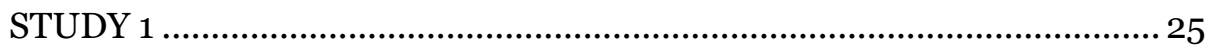

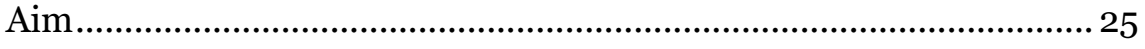

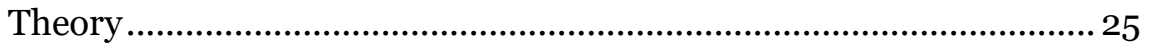

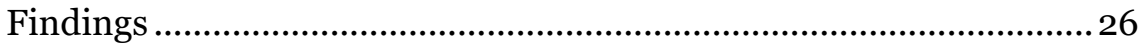

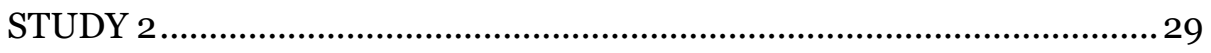

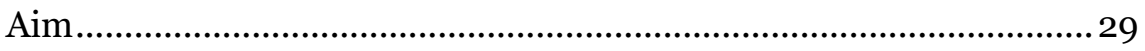

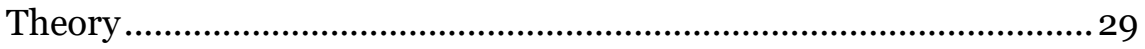

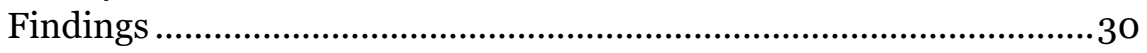

MAIN FINDINGS AND DISCUSSION ....................................................... 33

Legitimacy through the national guidelines......................................... 33

National guidelines and the risk of reinforcing a silo mentality..........34

The importance of context .................................................................... 35

FINAL REMARKS.................................................................................. 37

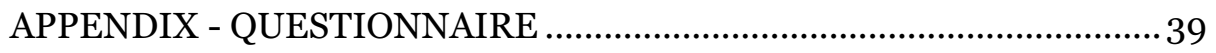

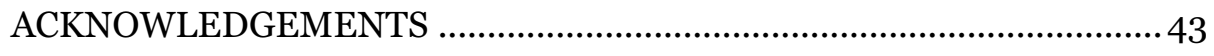

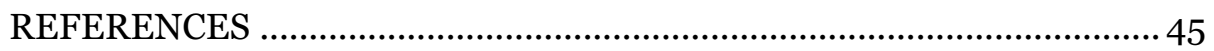





\section{ABSTRACT}

The purpose of this thesis is to explore the institutionally shaped response to the introduction of the national guidelines on the Swedish regional health policy arena. The thesis consists of two case studies. Adapting a qualitative approach, the data is based on individual interviews and these were analysed thematically. The first paper explores the response by four Swedish regional health authorities to the introduction of the National Guidelines for Cardiac Care, while the second paper aims to broaden the understanding of how the national guidelines are used for strategic purposes among politicians.

As illustrated in this thesis, organizations will respond, adjust and react to external pressure according to conditions shaped by the institutional context. Key findings here are that the national guidelines are a complex policy instrument that, beyond being able to be used in an instrumental fashion by the medical managment, can also serve a legitimizing function for political decision-makers.

The goals of the national guidelines, i.e. equal and efficient care, and the uncertainty about who, among multiple stakeholders, is responsible for the guidelines in the regional health authority, is a source of ambiguity and potential conflict. Those who are potentially responsible represent different rationales - a political rationale and a scientific rationale. The dominating scientific rationale of the national guidelines can create instability, when pushing towards the use of explicit priority-setting.

Priority-setting in the institutional setting of a regional health authority has strong elements of becoming "wicked problems" since the dilemma of prioritization remains regardless of ambitions to apply a "technocratic fix". A wicked problem is characterized by high complexity and being persistently hard to solve (Williams et al. 2012). A recurring dilemma is that priority-setting still contains many wicked problems, as social values and political considerations remain important parts of the policy process. One weakness of the national guidelines, identified in this thesis, is that the guidelines discuss each service area separately, and thereby reinforce a silo mentality in the Swedish health policy arena.

To sum up, the national guidelines create a multifaceted and complex response in the Swedish health policy arena where different rationalities collide, and where conflicts appear and are dealt with within the regional health authorities. 



\section{LIST OF PAPERS}

I. Kalkan, A., Sandberg, J., Garpenby, P. (2015) Management by Knowledge in Practice - Implementation of National Healthcare Guidelines in Sweden. Social Policy and Administration, 49(7), 911-927.

II. Sandberg, J., Persson, B., Garpenby, P. (online July 2018) The dilemma of knowledge use in political decision making - National guidelines in a Swedish priority-setting context. Health Economics, Policy and Law. 



\section{INTRODUCTION}

\section{Evidence in policy}

Since at least the early 1990 , the pressure on the health care system in Sweden and what this will imply for the future has been a source of lively public debate. Demographic changes and technological advances, leading to increasing costs and rising public expectations, are often put forward as explanations for why health care is under pressure. Hence, health policymakers in Sweden - whether on national, regional or local levels - are more inclined to find ways to make the best use of the resources available.

Against this background, increasing interest in the use of expert knowledge in a wider field of decision-making in the health policy arena is not surprising. An internationally prominent but inconclusive debate has flourished on whether expert knowledge is useful in health policy decisionmaking and for what it can be useful. Debates are often framed as a stand for or against what is sometimes labelled as evidence-based policy (EBP). Principles of evidence-based medicine (EBM), with its emphasizes on scientific research and positivist research methods, have influenced the concept of evidence-based policy-making (Black 2001, Boswell 2009, Greenhalgh \& Russel 2009, Ham et al. 1995, Lin 2003, Weiss 1979).

There has also been a debate on the barriers of using evidence in policymaking. In this debate several impeding factors have been highlighted, such as the deficit of relevant knowledge that can be used in the policy process, flaws in the interactive process between research and decision-making, and poor organizational capacity to enable knowledge transfer. These arguments imply that all knowledge that is available does not meet the requirements of decision-makers. Knowledge may be too general, too specific or not at all applicable for the specific decision to be made. Critics question the suitability and, sometimes even the relevance, of the use of evidence in policy-making. They often point to the complexity of the policy process and argue that this is an aspect that should not be underestimated (Black 2001, Boswell 2009, Greenhalgh \& Russel 2009, Ham et al. 1995, Jewell \& Bero 2008, Klein 2003, Lin 2003).

Considering the high profile of evidence within medicine, it is not surprising that the debate on the use of expert knowledge in policy-making has been especially prominent with reference to the health policy arena, distinguished by its high level of complexity (Plsek \& Greenhalgh 2001). There are several contributing factors to this high level of complexity. One important factor is what has been called the welfare dimension of health care. Sickness and health are unquestionably an area that evokes emotions, and 
this is at the heart of discussions on citizenship and the welfare state. Another factor is the power dimension, where the importance of health and health services can lead to conflicts between the wide range of stakeholders, such as patients, the medical profession, taxpayers and politicians (Freeman \& Moran 2000, Kuhlmann \& Burau 2008).

Adding to this, stakeholders within health care can represent competing types of rationales. Lin (2003) discusses the concept of competing rationalities to describe when participants in the policy process are informed by different types of rationality, which in turn may be related to different values, political goals or assumptions about the policy process. According to Lin, these rationalities exist as parallel truths and are mediated by institutional structures. In the health policy arena, the scientific rationale, with its high regard for positivistic science, is upheld by professional groups. In addition, the political rationale, which relates to the distribution of values and the management of power, is represented by elected officials who are accountable to citizens (Lin 2003).

The scientific rationale is strong in most health care systems, but in many countries the professional governance has been challenged by new scientific-bureaucratic regulation with managerial procedures and performance measurements. This can be said to limit the power of the medical professionals by increasing public control. At the same time, it may also reassert the power of medical professionals since it is based on the very same knowledge that the medical professionals produced. In this way, scientific-bureaucratic regulation may in fact both challenge and reinforce professional governance. Examples from Denmark and Norway show that "medical power is increasingly becoming a contested and publicly monitored arena of negotiations, where various players compete for 'evidence' and legitimacy of expert knowledge" (Kuhlmann \& Burau 2008 p. 630).

\section{Management by knowledge}

The ambition to reform medical governance in order to increase public control has appeared in different countries but has been expressed in different ways, or in other words, as different governance regimes. A governance regime is a country's context-specific pathway, created by diverse but co-existing forms of governance (Burau et al. 2009). In the governance of Swedish health care, with a decentralized system featuring independent regional health authorities, combined with clear national goals on equal and efficient care, management by knowledge has been put forward as a form of governance that is highly desirable in the health policy arena. The Swedish national guidelines are the most prominent policy instrument within this form of governance. The national guidelines are an interesting case be- 
cause of their multidisciplinary approach, but also because of their ambition, without any strong legal authority, to guide local decision-making through recommendations.

In a wider Swedish health policy context, the national guidelines are part of the scientific-bureaucratic regulation referred to as "management by knowledge" (Kalkan et al. 2015) or "informative governance" (Fredriksson et al. 2014). Management by knowledge is often referred to as a concept but is not easily defined. It is not primarily defined by its components but rather by the way it is based on knowledge having a particular basis of legitimacy (Garpenby \& Carlsson 1999). It refers to the intention to move decision-making in the health care sector, including policy decisions, in the direction of becoming more evidence-based (Bijker et al. 2009, Ferlie et al. 2009). Although there are some differences in their interpretations, management by knowledge and evidence-based policy-making are similar concepts.

Management by knowledge raises the immediate question of what entails knowledge. To some, knowledge is narrowly defined as evidence produced by scientific methods, while a broader definition could also include other forms of knowledge used for decision-making (Nutley et al. 2007). The concept of knowledge is also understood differently depending on what perspective is taken on how policy is made. In the more simplistic linear models, knowledge is like a package that can be handed out. However, knowledge can also be understood as part of a system where it is necessary to consider the interdependence and interaction between culture, structure, preference and capacity (Best \& Holmed 2010). With this perspective, it is of key importance to take contextual factors into consideration when deciding on what is relevant knowledge and how this knowledge should be used (Dobrow et al. 2004).

As a policy-instrument, management by knowledge can be understood as a form of soft law or non-legislative mode of governance. In the continued ambition of the Swedish central government and state agencies to ensure efficient, knowledge-based and equal care, there has been an increased use of soft-law policy instruments such as agreements, monitoring and input of expert knowledge. Soft-law governance also includes various forms of informal social pressures, such as shaming, peer pressure and moral responsibility, with the goal of making the institution conform. In Sweden, soft-law can be considered a practice to overcome the central-local divide of the decentralized health care system. It becomes a way to combine local autonomy with coordination of national policy (Fredriksson et al. 2012).

In this thesis, the ambition is to explore the institutionally shaped response to the introduction of national guidelines, as an example of expert knowledge, in the Swedish regional health policy arena. Expert knowledge is not easy to define. Instead of providing a specific definition, e.g. that this 
is knowledge that draws on specific scientific methods, I will argue that expert knowledge in large part is defined by its context. For example, what is regarded as expert knowledge may vary depending on who is considered to be an authority and have the legitimacy to be used as an expert. The expert knowledge in focus in this thesis is the Swedish national guidelines as a specific form for packaging knowledge, characterized by being researchbased and multidisciplinary, and drawing on both clinical research and health economics but also containing a political rationale. It was introduced by the National Board of Health and Welfare with the objectives to actively (1) attain more efficient care, (2) reduce regional disparities and (3) increase implementation of evidence. The means to achieve these goals is the use of the national guidelines as a knowledge base for prioritization at regional health authority level.

\section{Resource allocation and priority-setting}

Perhaps one of the most controversial fields of decision-making in public health care systems today is resource allocation and priority-setting (McCaughey \& Bruning 2010, Robinson et al. 2012, Saarni \& Gyllin 2004, Syrett 2003). The priority-setting process within health care, where both facts and social values have to be considered, has been described as containing elements of both tame and wicked problems. A wicked problem is a problem where the solution is not evident and where there is a high risk of resistance and conflict. Here, expert knowledge may be useful but not sufficient. Tame problems are of a simpler nature and only require a targeted solution and implementation in a more linear fashion (Dickinson et al. 2011, Williams et al. 2012, Williams 2015). Dickinson et al. (2011) argue that a problem in the current debate is the tendency to consider prioritysetting only as a tame problem. Instead, priority-setting should be identified as the highly political process that it is, involving a complicated web of actors and considerations. Framing priority-setting as a wicked problem can bolster the legitimacy and authority that is needed to respond adequately (Dickinson et al. 2011).

Resource allocation and priority-setting are often a sensitive topic for politicians, involving difficult ethical dilemmas, and these decisions are assumed by politicians to be unpopular with the public. It is considered difficult to win support for priority-setting decisions and therefore, despite arguing for transparent processes, politicians have a tendency to distance themselves from priority-setting (Ham \& Coulter 2000, Robinson et al. 2012, Saarni \& Gyllin 2004). One strategy of blame avoidance is for politicians to refer to protocol or standards, be they rules or routines, a protocolization approach. Guidelines based on expert knowledge, such as national guidelines, are an example of a standard that can be used as a defence 
for politicians against the conflicting requirements from party politics, the mass media, organized interests, citizens and patients (Boswell 2009, Hood 2011, Syrett 2003). Politicians often prefer a technocratic method to solve the ethical and economic dilemma of health care and, by doing so, avoid political controversy (Syrett 2003). Such an approach can however be used to diminish the fundamentally political nature of priority-setting in health care (Klein 1993).

\section{Aim and overview}

Increased pressure is being put on the Swedish health care system to incorporate knowledge into the policy process and to make decisions that make the best use of the resources available. It is against this background that the aim of this thesis is to explore the institutionally shaped response to the introduction of the national guidelines in the Swedish regional health policy arena. Important questions in this thesis are how the Swedish regional health authorities respond to the institutional pressure exerted by the national guidelines, how the institutional response can be explained when using particular theoretical frameworks, and thus how strategic response can be understood depending on the contextual factors. This thesis consists of two case studies with results that are presented in two papers. The first paper, Management by Knowledge in Practice - Implementation of National Healthcare Guidelines in Sweden (Kalkan et al. 2015), explores the response by four Swedish regional health authorities to the introduction of the National Guidelines for Cardiac Care (NGCC). The second paper, The dilemma of knowledge use in political decision making - National guidelines in a Swedish priority-setting context (Sandberg et al. 2018), aims to broaden the understanding of how the national guidelines are used for strategic purposes among politicians.

The thesis will have the following structure. In this introduction, the topic of this thesis has been introduced, including the aim of the study. In the following chapter, the ambition is to give a background to facilitate an understanding of the cases presented in this thesis by an introduction of the theoretical framework, the Swedish health policy arena and national guidelines as a policy instrument. Then, I will discuss the methodological choices made and reflections on the methodological stands taken in the thesis. Thereafter, the aim, theory and findings of study 1 and study 2 will be summarized. The following chapters discuss the main findings of the thesis and lastly some final remarks are presented. 



\section{BACKGROUND}

\section{Theoretical framework}

When the ambition is to explore a case of an institutionally shaped response, the most evident starting point for a theoretical framework is institutionalism. The institutionalist approach stresses the taken-for-granted rules and practices as crucial in forming the institutional context, which then frames preferences and strategic options. March \& Olsen (1996) state that "Institutional theories similarly emphasize the ways in which institutions shape the definition of alternatives and influence the perception and construction of the reality within which action takes place" (p. 251). Institutionalism is sometimes described as an approach rather than a coherent theory, and the field of institutionalism can be separated into different schools of thought or perspectives, i.e. rational choice and historical institutionalism (Hall \& Taylor 1996, Thelen 1999, Peters 1999, Powell \& DiMaggio 1991).

The theoretical framework of this thesis is inspired by a sociological institutional perspective. The perspective originated as a subfield of organizational theory at the end of the 1970s. The sociological institutional perspective came as a reaction to the then dominant assumption that organizations are formed in a rational way based on arguments of efficiency. According to this thinking, individuals have desires and preferences that are aggregated as collective action by bargaining, negotiations and the building of coalitions (March \& Olsen 1996). However, a key question asked from the perspective of sociological institutionalism is why an institution chose certain forms, procedures and symbols. The argument is that institutions should be seen as culturally-specific practices that, beyond being formed by formal rules, are also, to a significant extent, formed by norms, values, myths and ideas. Hall \& Taylor (1996) identify three distinct features of sociological institutionalism: (1) a wide definition of institution including norms, values, myths and ideas, (2) a view on individual preferences, identity and action as shaped by internalized norms associated with institutional roles, and (3) institutional change considered as a result of an organization striving for social legitimacy (Hall \& Taylor 1996, March \& Olsen 1996). This thesis relates to the sociological institutional perspective and the outlook on institutions presented by March and Olsen (1996). The main theoretical contributions used in the studies are the work of Christine Oliver (1991) and Christina Boswell (2008, 2009), both of whom can be said to be inspired by the sociological institutional perspective and its interest in institutionally shaped responses. 
In the studies of this thesis, particular attention is paid to how institutions respond to external pressure and how this response is not rational but highly context-dependent. Institutional context can include rules, practices and structures of meaning that are persistent beyond easily changing circumstances. The institutional context gives structure in times of institutional pressure, and actors organize and act as anticipated in accordance with the dominant rules and practices. The logic of appropriateness is the basis on which action is taken, that is, appropriate in relation to roles, routines, obligations, standard practice and procedures (March \& Olsen 1996).

Oliver (1991) takes a particular interest in how institutionalization influences organizational environments and shapes strategic responses. In her approach, she focuses on the significance of power and agency and calls for "an expansion of the choice set available to organizations" (Scott 2008 p. 169). Starting with her reasoning on resource-dependency, she then presents a broad range of potential responses to institutional pressure. In her work, Oliver emphasizes that the context of the institution determines the strategies that the institution chooses when experiencing institutional demands and expectations. According to Oliver, organizational responses to institutional pressures will depend on five crucial factors: cause, constituents, content, control and context. Depending on these factors, five general strategies are predicted as responses by organizations experiencing institutional pressure: acquiescence, compromise, avoidance, defiance and manipulation. The typology of strategic responses presented by Oliver is described further in the chapter on study 1.

Like Oliver (1991), Christina Boswell (2008, 2009) attempts to explain what can be expected when an organization is exposed to institutional pressure. Boswell $(2008,2009)$ states that her theory can be placed within an organizational institutionalist approach where the premise is that organizations are concerned with meeting societal expectations in terms of structure, practices, rhetoric and output (Boswell 2008). Boswell's reasoning is mainly about how different organizational and political conditions affect how knowledge is used. She takes as her starting point in the assumption that the value of expert knowledge for policy-makers does not only lie in its contribution to solving problems (instrumental function), or even in filling an enlightening function. Instead, she argues that knowledge more often fulfils an important symbolic function for policy-makers. Boswell differentiates between two types of symbolic use. Firstly, a legitimizing function, which means that an organization tries to draw on knowledge to "[...] enhance its legitimacy and potentially bolster its claim to resources or jurisdiction over particular policy areas" (Boswell 2009 p. 7). Other authors have called this political-strategic (Schrefler 2010) or tactical (Weiss 1979) usage of knowledge (cf. Radaelli 1995). Secondly, a substantiating function of expert knowledge, which means using knowledge to lend authority to a 
specific argument or policy position. This use of knowledge can for example serve to legitimize a decision that has already been made, or as ammunition in an adversarial context (cf. Schrefler 2010).

A central aspect of Boswell's perspective is the reasoning on how different organizational and political conditions affect how knowledge is used. Boswell argues that different organization types encourage different uses of knowledge. While so-called action organizations primarily derive their impact from their concrete output, political organizations primarily derive their legitimacy from formal structures and decisions. Action organizations can primarily be expected to use knowledge in an instrumental fashion, solving problems to increase output. Both political organizations and action organizations can be expected to use expert knowledge to validate their claims, but a political organization is more likely to use expert knowledge as a source of legitimation compared to an action organization (Boswell 2008, 2009). Boswell's approach to legitimacy and organization types is further developed in the chapter on study 2.

\section{Setting the scene - the Swedish health policy arena}

The studies in this thesis are both situated in the Swedish health care arena. In Sweden, health care is tax funded and accessible for all 10 million inhabitants. The country is sub-divided into 21 regional health authorities (including Gotland) ${ }^{1}$ and 290 municipalities. Most municipalities are responsible for health care in the home, mainly for the elderly and the chronically ill. However, the regional health authorities are responsible for the majority of the Swedish health service and its responsibility is to provide primary, secondary and tertiary care services. In this thesis, the focus will therefore only be on the regional health authorities. These are run by directly elected politicians with a high degree of decentralized power. They have the right to levy taxes and decide on how resources are distributed between different service areas. To a large degree, the regional health authorities also decide on the organizational form that is perceived as most appropriate in relation to the conditions of the specific authority. For the more advanced health care services, requiring major investment and specialized knowledge, the regional health authorities collaborate within health care regions.

Even though health care in Sweden is a decentralized system, the national level plays an important role. The Health Care Act (SFS 2017:30) stipulates that the goal is to achieve good health and care on equal terms for the entire population. Good quality and high accessibility are aspects of good care that are highlighted in the Health Care Act. The Swedish health

\footnotetext{
${ }^{1}$ The regional health authorities were referred to in the first study as county councils but are referred to in the second article and this thesis as regional health authorities.
} 
policy arena can be described as an interplay between the national level and the regional level. The ambition of the national level is to preserve a system with strong traits of health care provided to the whole population on equal terms. Historically, at national level, the central government and the state agencies used a variety of policy instruments such as legislation and economic incentives to influence the regional level. The result has varied, and today unequal health care is placed high on the Swedish political agenda. Today, a wide range of policy instruments are used to achieve a comprehensive system. As Sweden is characterized by its decentralized health care system, however, this will give the regional authorities an independence to shape their own policy. From a democratic standpoint it gives the constituents a greater possibility to influence health care policy. Through the benefits of proximity, an argument is also made for increased efficiency when there is a possibility to adjust to local needs and conditions (Fredriksson 2012, Magnussen et al. 2009). Beyond the pressure from the national level, the regional level must also respond to pressure from different stakeholders in the local context (e.g. medical professionals, citizens, patients, interest groups and the media). A complex web of considerations leads to a great variation in the local needs and conditions, and thereby creates a wide range of institutional contexts within the Swedish health care system.

The main government agency at national level is the National Board of Health and Welfare (NBHW, Socialstyrelsen), which comes under the Ministry of Health and Social Affairs. The agency has declared an ambition to be a hub when it comes to national management by knowledge. Management by knowledge is defined by the state agency as the development, dissemination and use of the best available knowledge. The goal is to make this knowledge available and used. Guidelines, recommendations and access to data and registers are mentioned as examples of management by knowledge.

\section{Understanding a policy instrument - national guideli-}

\section{nes}

Management by knowledge can take different forms and a variety of policy instruments have been used in the Swedish health policy arena, for example agreements between central government and the regional health authorities, represented by the Swedish Association of Local Authorities and Regions (Fredriksson et al. 2012). A main policy instrument within management by knowledge has been the national guidelines. National guidelines were presented by the National Board of Health and Welfare to offer a cohesive knowledge base for prioritization at regional health authority level. The concept was first introduced in the 1990 s and later developed in 
the early 2000s, when the National Guidelines for Cardiac Care became the first guidelines in the new form.

National guidelines emerged at a time when transparency in health care put regional variations on the agenda (Blomgren \& Sahlin 2007). In addition, economic austerity increased the awareness of a need for explicit prioritization (Carlsson 2010). As a policy instrument, the national guidelines aim to influence decision-making by offering a knowledge base but without having any legal authority. The National Board of Health and Welfare emphasizes that the national guidelines are a means of support for those who make decisions concerning the allocation of resources within health and medical care and social services. The objectives of the national guidelines are to actively (1) attain more efficient care, (2) reduce regional disparities, and (3) increase implementation of evidence. The overall goal is to contribute towards patients and clients receiving a high standard of medical care and social services.

The National Board of Health and Welfare is responsible for drawing up national guidelines and deciding in which areas national guidelines are most needed. Severe, often chronic diseases that require extensive resources are prioritized. Today, there are guidelines in 14 different areas, ranging from dementia to cardiac care. In addition, guidelines are being produced in four more areas.

Once it has been decided that national guidelines are needed within a service area, the state agency appoints experts to multidisciplinary working groups to produce the guidelines. The project is coordinated by a professional project manager from the National Board of Health and Welfare, which also finances the work. The multidisciplinary working groups consist of experts within the specific field as well as other professionals representing the entire chain of care. The expertise of health economists is also a vital part of this work, and health economics is integrated into the evidence base in the national guidelines. The document is problem-based and focuses on areas where there is need for guidance for professionals and other decisionmakers (Grip et al. 2011).

As a final document, the national guidelines give recommendations on what prevention, diagnosis, treatment and aftercare is available within a specific field. The interventions are ranked from one to ten, using a national model for transparent prioritization (severity, patient benefit and cost-effectiveness) that draws on the ethical platform for health care. The ranking includes an account of the organizational and economic effects that the interventions can be expected to have. There is also a list of interventions that should not be utilized at all or on a routine basis, as well as a list of interventions where there is a lack of sufficient evidence. High priority is given to interventions with a large medical benefit and a low cost per QALY (quality-adjusted life year) gained. The priority grading is carried out within a 
transparent process where patient organizations, political decision-makers and relevant specialist associations are consulted. There is also an open consultation round and conferences to get additional comments before presenting the final results online and in print. Quality indicators within the service area are used to follow up on the results (Grip et al. 2011).

Attention has been paid to the process of drawing up guidelines, especially in connection with the challenges of choosing relevant knowledge and coming to an agreement (Eckard et al. 2017, Fernler 2015). For example, the concept of informed ignorance has been used to describe how it is not possible to include all relevant knowledge in guidelines. There needs to be a selection process in order to draw up stable and coherent guidelines, and this selection is not random but rather informed. In this way, informed ignorance is both an obstacle and a necessity in the policy process (Fernler 2015). Eckard et al. (2017) have specifically studied how the groups working on the National Guidelines for Cardiac Care came to an agreement. The conclusion is that tensions that arise in the working groups are, to a large extent, dealt with through open deliberation. Negotiations and collaboration are significant traits in the process of devising the National Guidelines for Cardiac Care, and competing rationalities are addressed within the organizational frame (Eckard et al. 2017).

Even though the national guidelines are based on medical evidence, they represent a multifaceted policy instrument that has implications for both clinical and political decision-making (Grip et al. 2011). In comparison to more traditional guidelines for clinical practice, the Swedish national guidelines are different since, in addition to the scientific rationale, they also include a political rationale. The political rationale comes from the ethical platform for health care, issued by the Swedish Parliament, which stresses the ethical principles of human dignity, need-solidarity and cost-efficiency/effectiveness when making priorities (Calltorp 1999, Eckard et al. 2017). In sum, aside from being clinical guidelines, the national guidelines also represent a societal perspective on health care. 


\section{METHODS AND MATERIAL}

This thesis consists of two case studies. In the first study, the responses from four Swedish regional health authorities to the introduction of the National Guidelines for Cardiac Care (NGCC) are explored, and in the second the focus is on how the national guidelines are used for strategic purposes by politicians. The two case studies draw on the same data set. Therefore, the presentation here will describe the methodological approach and only highlight relevant methodological differences between the two studies. The table below contains a brief summary of the design, method, participants and analysis in the two case studies. A more thorough review of all parts will be presented further on in this chapter.

Table 1. Summary of the design, method, participants and analysis.

\begin{tabular}{|l|l|l|l|l|}
\hline Study & Design & Method & Participants & Analysis \\
\hline I & $\begin{array}{l}\text { Qualitative, } \\
\text { case study }\end{array}$ & $\begin{array}{l}\text { Individual } \\
\text { interviews }\end{array}$ & $\begin{array}{l}\text { 155 politicians, admin- } \\
\text { istrators and clinical } \\
\text { managers }\end{array}$ & $\begin{array}{l}\text { Thematic, } \\
\text { abductive }\end{array}$ \\
\hline II & $\begin{array}{l}\text { Qualitative, } \\
\text { case study }\end{array}$ & $\begin{array}{l}\text { Individual } \\
\text { interviews }\end{array}$ & 11 politicians & $\begin{array}{l}\text { Thematic, } \\
\text { abductive }\end{array}$ \\
\hline
\end{tabular}

\section{Choice of method - case studies}

To understand as complex a phenomenon as the institutionally shaped response to the introduction of a policy instrument that draws on knowledge processed by experts, a qualitative approach is to be preferred. Yin (2003) describes a case study as "an empirical inquiry that investigates a contemporary phenomenon within its real-life context, especially when the boundaries between phenomenon and context are not clearly evident” (p. 13). As with any method, case studies have both strengths and weaknesses. A prominent strength of the case study is the ability to achieve high conceptual validity, i.e. that a measure measures what it intends to measure. This strength is displayed in this thesis, as the intention is to study the complex phenomena of introducing expert knowledge in an organizational setting. The multifaceted response is expressed in the nuances, and at times contradictions, in the answers given by the informants.

It is also important to pay attention to the limitations of using the case study as a method. One such limitation is case selection bias, causing a risk that occurs at the very start of a study and includes the danger of selecting 
a case that is significantly different from that of a corresponding case (George \& Bennett 2005). The cases in this study are a selection of regional health authorities, chosen with the intention of achieving a diversity in conditions. A risk is that the regional health authorities knew they were being studied may have affected the way they chose to handle the introduction of the National Guidelines for Cardiac Care. The service area selected for inclusion in the study, cardiac care, could also have implications. Cardiac care is generally considered a high-status area within health care. It is important to be aware of the risk that the national guidelines for this specific service area could be given more attention than others due to the status of the particular service area.

A common criticism of case studies is that they do not offer a result that can be generalized. Yin (2003) argues that this criticism comes from a misconception of the difference between statistical representation and analytical generalization. Analytical generalization can be understood as the ambition to generalize results in relation to a broader theory. By replicating the findings, the theory can be tested and possibly confirmed. The credibility of qualitative studies is mainly based on performing studies in a systematic and transparent way. The reader can thereby assess to what extent the results can be applied in a wider perspective.

\section{Selection of cases and informants}

The studies in this thesis are descendants of an original study that began in 2004 and was later continued in 2007, with a modification in the selection of informants (more on this below). The results of the original study have been presented in two Swedish reports (Garpenby et al. 2005, Garpenby et al. 2007). In this thesis, data from a third round of interviews in 2011 is mainly used.

As previously stated, the first study was performed in 2004. When the National Guidelines for Cardiac Care were published, Linköping University was commissioned by the National Board of Health and Welfare to explore the implementation of the guidelines. The National Board of Health and Welfare selected four of the 21 regional health authorities in Sweden to be included in the study: Skåne, Sörmland, Västra Götaland and Västernorrland. The selection was made to ensure diversity in certain conditions and characteristics - different geographical locations, population sizes and areas of responsibility, such as responsibility for, and access to, a university hospital. These were local conditions that were believed to be relevant for attaining the goal of diversity. The choice was not based on theory, however, but on an ambition to cover a cross-section of Swedish regional health authorities. Even considering the risk of case selection bias, a strength of 
the study is that it comprises informants from as many as four of the 21 regional health authorities in Sweden.

Since the start of the original study, there have been three rounds of data collection over a period of seven years: 2004 (74 interviews), 2007 (45 interviews) and 2011 (36 interviews). On each occasion, a research group has been responsible for collecting the data. One member has taken part in all three studies. The author of this thesis was part of the research group in 2011. The first paper in this thesis uses material from all three rounds of data collection, but with a focus on the data from 2011. The second paper only uses part of the data from the round of data collection in 2011.

In the first round of interviews, the informants were initially chosen by purposeful sampling and additional interviews were then carried out based on snowball sampling, resulting in an extensive amount of material. In the second and third rounds, the participants were chosen by purposeful sampling. In all three rounds, purposeful sampling was carried out with the help of a contact person at each regional health authority. The participants were selected on the basis that their role gave them an insight into the specific knowledge of the implementation of the National Guidelines for Cardiac Care in the regional health authorities. Purposeful sampling, with strategically selected informants, gave in-depth information on the research questions at hand (Patton 1990). This way of choosing participants is especially appropriate when exploring processes that involve people who have a valuable insight into the issue at hand (Bogner et al. 2009), such as the processes studied in this thesis. A limitation of this type of sampling is the risk that some unrepresented expert points of view might not be covered. Access to key actors in the regional health authority is very important and was facilitated by a contact person within each regional health authority. The regional health authorities were willing to participate, and when asked to share their experiences in an interview setting, the informants accepted.

The major difference between the two case studies included in this thesis concerns the informants included. The first case study includes informants from all three instances of data collection and from all three categories of informants - politicians, administrators and clinical managers. These three categories are involved at different levels of the hierarchy, but they all represent groups identified as important by the National Board of Health and Welfare concerning the implementation of the national guidelines.

Data was collected in 2004, 2007 and 2011. The use of data from different periods in time reflects the need for a long timeframe to analyse such a complex process, as pointed out by, for example, Sabatier (2007). The main strength of this study is that it covers the perspectives of different actor groups in the organization. A limitation of this ambitious approach was the difficulties associated with such extensive material. 
In the second case study the focus was on politicians, hence the selection of informants was narrower. All the interviews with politicians in 2011 were used, a total of 11 interviews out of the 36 interviews conducted in 2011. The ambition has been to strategically select informants with a role that gives them an insight into the implementation of the National Guidelines for Cardiac Care and specific knowledge of the national guidelines as an example of expert knowledge, within the regional health authorities. Given this ambition, there was also an evident limitation of possible informants.

\section{Interviews and analysis}

The interviews were performed at a location chosen by the informant and lasted approximately 30-75 minutes each. All interviews were recorded and transcribed verbatim. The informants were informed about how the collected data would be analysed and presented. They also gave their consent for recording before the interview started. Concerning the round in 2011, ethical approval was provided by the Regional Ethical Review Board in Linköping in May 2011 (Dnr. 2011/126-31.)

The interview guide was constructed by combining closed and openended questions, giving the participants an opportunity to add information they considered relevant (Kvale 2009). The participants were asked questions about the National Guidelines for Cardiac Care specifically, but also questions of a general nature relating to national guidelines.

In both studies, a thematic analysis was carried out to elucidate the essence of the data (Boyatzis 1998). In the first study, the data was analysed by two authors separately, and the coding was thereafter compared and discussed, generating the final themes. In the second study, the thematic analysis was conducted by a meticulous reading, to capture the general themes, and the data was later scrutinized in greater depth in collaboration between three authors. A limitation, as is always the case with qualitative research, is whether the thematic analysis has captured the most important aspects. Involving several authors in the analysis and then discussing it together is one way to increase the reliability of the study.

In social science, a common methodological divide is made between an inductive and a deductive approach. The divide between inductive and deductive has been criticized for being too definite and not being of use in case-study research (Alvesson et al. 2018). Hybrid approaches, including both inductive and deductive traits, have been presented (Fereday \& MuirCochrane 2006, Flick 2009). Abduction, when a case is interpreted from a hypothetical main pattern and then strengthen by new observations, has 
been put forward as an alternative to the inductive-deductive scale (Alvesson et al. 2018). In this thesis, since the analysis was underpinned by theoretical conceptions, it had characteristics of deduction. At stages in the analysis, a framework was used where theoretical concepts from Matland (1995) and Oliver (1991) (study 1) and from Boswell (2008, 2009) (study 2) were used. However, it also has traits of induction as it was open to reflexivity and new understandings when analysing the information. Hence, abduction is a suitable way to describe the course of action in this thesis. 



\section{STUDY 1}

\section{Aim}

In the first study, the aim is to explore the responses of four Swedish regional health authorities to the National Guidelines for Cardiac Care. Launched in 2004, as the first document of its kind, the guidelines aimed to influence both clinical and political decision-making in the health care arena.

\section{Theory}

Theoretically, the study draws on the theoretical contributions of Christine Oliver (1991) regarding strategical response and Richard E. Matland's ambiguity-conflict model of policy implementation (1995).

The theoretical contributions of Christine Oliver (1991) have a specific focus on strategic response to institutional pressure. According to Oliver, organizational responses to institutional pressures will depend on five crucial factors and the answers to five basic questions. The first factor is cause, that is why the pressure is being exerted. Change toward conformity will probably occur if an organization considers it likely that an adjustment will lead to increased social fitness/legitimacy and economic fitness/efficiency. The second factor is constituents, that is who is exerting the pressure. Change toward conformity will more likely occur if there is a low degree of institutional constituent (e.g. the state, professions, interest groups, the general public) and if there is a high degree of external dependency on pressuring constituents. Third, content, that is the substance of the pressure. Change toward conformity will more likely occur if the organization approves of the content of the suggested change or how the pressure takes form, for example the choice of policy instrument. The fourth factor is control, that is how and by what means pressure is exerted. Change toward conformity will here more likely occur if there is legal coercion behind. Last, the fifth factor is context, that is where the pressure occurs. Change toward conformity will more likely occur if the organization is experiencing environmental uncertainty and if there is a high interconnectedness between organizations within a field. In general, organizations strive for certainty and predictability.

Depending on the answer, Oliver predicts five general strategies as responses by organizations experiencing institutional pressure: acquiescence, compromise, avoidance, defiance or manipulation. In sum, Oliver

emphasizes that the context of the institution determines the strategies that 
the institution chooses when experiencing institutional demands and expectations, whether it chooses a strategy to resist or to conform. The theory can help us understand why an organization chooses a certain institutional response.

In Matland's ambiguity-conflict model of policy implementation (1995), the focus is on the characteristics of policies. Historically, research on policy implementation has been divided into two schools of thought: top-down and bottom-up. While top-down theorists view the design of policy as central, bottom-up theorists emphasize the role of local level service deliverers (Hill and Hupe 2009). Matland's ambition was to reconcile these two schools of thought in an ambiguity-conflict model of policy implementation. In this model, the emphasis is on the importance of policy characteristics on how implementation evolves. According to Matland, the implementation of an individual programme or policy depends on the degree of conflict and ambiguity, in terms of both the goals of a policy and the means with which to implement it. The implementation process is also highly influenced by local conditions, such as resources, distribution of power, activities and coalitions. According to Matland, policy implementation should always be understood as a result of a strategic response in organizations with particular traits.

\section{Findings}

At the time of their introduction, there was wide support for the goals of the National Guidelines for Cardiac Care in all regional health authorities included in the study and by all categories of informants - politicians, administrators and clinical management. Evidently, the document seemed to be perceived as legitimate and important. However, a closer look at the statements made by the informants indicated that the interpretation of the goals varied between the categories of informants. The open-ended questions also resulted in mixed messages where some informants first made statements in support of the national guidelines while later questioning the meaning of the goal of equal care. Hence there was initially a high degree of ambiguity inherent in the policy, related to the goals of the policy.

Statements from the informants also suggested that the strategies for achieving the goals in the National Guidelines for Cardiac Care were perceived as vague. They did not initially express the opinion that the document provided input for local health care programmes, supported explicit and needs-based prioritization or increased the dialogue between decisionmakers, which was an important reason why the guidelines were drawn up to begin with. A clear view of how to handle the National Guidelines for Cardiac Care was lacking, and there was also a high degree of ambiguity regarding how the guidelines should be implemented. To begin with, the 
level of ambiguity was high in both the goals of the policy and the means for implementing it. At this early stage, the levels of conflict were low. However, with time, local level coalitions took a larger role in the process. The increased involvement of local professional networks eventually raised more intense questions at the administrative and political levels of the regional health authority about funding. This resulted in fierce debates with the administrative and political branches, leading to an increased level of conflict. The increase in conflict surrounding how to conform to the pressures of the National Guidelines for Cardiac Care related to explicit prioritization. The pressures put on the different branches of the regional health authority by the guidelines were confronted in different ways. The clinical management wanted to comply with them, seeing them as aligned with their goals, while at the same time full compliance needed explicit prioritization by politicians. The politicians, on the other hand, explained that they did not fully grasp the implications of the guidelines.

To begin with, the reasons for introducing the National Guidelines for Cardiac Care were economic restraints and an ambition for more equal care within Sweden. Even though the goals were considered vague by the informants and not all informants saw themselves as recipients, they still stated that the regional health authority intended to conform. Although it is clearly stated by the National Board of Health and Welfare that the National Guidelines for Cardiac Care are intended for decision-makers throughout the entire health care organization, when the guidelines were released, politicians and administrators mainly saw them as something for clinical management and medical professionals.

The ambiguity of the policy in combination with the large number of constituents in the Swedish health policy arena (e.g. politicians, medical professional, administration, patients, state agency) worked as a force to inhibit conformity. Also, the content, although not publicly contested, followed a scientific rationale that was not evident to the politicians. Additionally, the national guidelines were part of a wider range of external pressures that confronted the regional health authority. The external pressure came in different forms such as laws and regulations, comparisons of performance between regional health authorities and pressure from patients and the public with reference to the guidelines. The process of introducing the national guidelines did not gain the momentum requested by the medical management, and without any control mechanisms such as legal penalties, this did not move the organization quickly towards conformity. However, the environmental uncertainty and high degree of interconnectedness favoured conformity, similar to the factors described as the reasons for introducing the guidelines. However, the question remains whether the Na- 
tional Guidelines for Cardiac Care were actually used in explicit prioritization or whether the structure of implementation was a way to disguise nonconformity behind a façade of acquiescence. 


\title{
STUDY 2
}

\begin{abstract}
Aim
In the second study, the aim is to broaden the understanding of how a policy instrument, embracing both a scientific and a political rationale and intended for priority-setting at regional level, the national guidelines, is used for strategic purposes. The study analyze how Swedish health care politicians perceive and make use of this policy instrument when trying to uphold the requirements of health care, as both a political and an action organization.
\end{abstract}

\section{Theory}

The theoretical tools in the second study were provided by Christina Boswell's reasoning on how different organizational and political conditions affect how knowledge is used. Boswell (2009) argues that the important value of expert knowledge for policy-makers is its symbolic function. The symbolic use of expert knowledge can be for the legitimizing function or its substantiating function. The legitimizing function refers to when an organization tries to draw on knowledge to "enhance its legitimacy and potentially bolster its claim to resources or jurisdiction over particular policy areas" (Boswell 2009 p. 7). The substantiating function of expert knowledge, on the other hand, entails using knowledge to lend authority to a specific argument or policy position. This use of knowledge can for example serve to legitimize a decision that has already been made, or as ammunition in an adversarial context. This contrasts with a traditional view of expert knowledge as input for solving problems (instrumental function) or to enlighten policy-makers.

Boswell also highlights how different organizational and political conditions affect how knowledge is used and how different organization types encourage different uses of knowledge. The two types of organizations that are put forward are action organizations and political organizations. Action organizations primarily derive their impact from their concrete output and usually use knowledge in an instrumental fashion, solving problems to increase output. Political organizations primarily derive their legitimacy from formal structures and decisions and are therefore more likely to use expert knowledge as a source of legitimation compared to an action organization. 


\section{Findings}

As previously stated in the first study, the informants expressed a positive attitude towards national guidelines in general and the National Guidelines for Cardiac Care more specifically. All politicians considered the national guidelines to be a document with high credibility, and the process of drawing up the guidelines was given credit for this. The high profile of the National Guidelines for Cardiac Care made it a facilitator in the local context. Examining the role of the politicians, it became evident how political decision-makers made use of the national guidelines to legitimize their role.

The politicians expressed an appreciation of the concept as such, as they focus on how well it serves the purpose of legitimizing the national political objective of equal quality of care for all citizens. The participants describe several underlying problems with the application of the guidelines, foremost, difficulties for the regional decision-makers to maintain their independency in relation to central government, and the dilemma of advantages given to service areas covered by national guidelines. A major theme among the politicians was the problems they experienced in getting the guidelines to support a local process of prioritization, and thus facilitate the ability of politicians to take full responsibility for the overall budget and its distribution between different service areas. Several of the politicians described a situation where each set of guidelines tended to be an isolated silo, resulting in a narrow process that risked excluding contextual factors and other service areas.

The politicians described problematic situations where the scientific and political rationales collide, and they had to relate to the requirements of both the political and the action organization represented by strong professionals. Although there is a political rationale in the national guidelines, it did not necessarily coincide with the rationale displayed by the regional politicians. Several of the politicians underlined that they experienced difficulties in using the national guidelines as unambiguous facts, as they had to position themselves in relation to the facts pertaining to many guidelines. The collision between different rationales and the need to strike a balance between the requirements of a political and an action organization stands out in the priority-setting process of the regional health authorities.

Since the regional health care politicians' initial situation was not strong, they hoped that the national guidelines would help them to legitimize their role vis-à-vis the most prominent representatives of the action organization, the medical management. As the politicians find themselves in the midst of a conflicting situation, where they constantly have to balance the requirements of a political organization with that of an action or- 
ganization, they viewed the national guidelines as an important policy instrument for reaching the medical managment and finding common ground on which to meet and deliberate. 



\section{MAIN FINDINGS AND DISCUSSION}

\section{Legitimacy through the national guidelines}

The knowledge focus in this thesis is a specific form of expert knowledge, produced by expert groups, and embedded in a policy instrument. This policy instrument - the Swedish national guidelines - is characterized by being research-based and multidisciplinary, drawing on both clinical research and health economics but also containing a political rationale. This is a complex policy instrument, but the form of standardization of knowledge represented in this policy instrument has the ability to attract several of the important stakeholders in the health care policy arena. Beyond being able to be used in an instrumental fashion by the medical management, it also has the ability to serve a legitimizing function for political decision-makers. Consequently, even in situations where it may look as if this expert knowledge is not used, it may in fact play an important, yet subtle, role by enabling decision-makers to lend authority and legitimacy to a process and/or a decision (Boswell 2008, 2009). For the politicians in the Swedish health policy arena, at regional level, the national guidelines fulfil a legitimizing function. Using expert knowledge of this kind to attain legitimacy can be understood as facilitating the ambition of organizations to function as smoothly as possible.

Swedish regional health authorities are both action organizations, primarily deriving legitimacy from their concrete output, and political organizations, primarily deriving their legitimacy from formal structures and decisions (Boswell 2008). Action organizations and political organizations require different uses of knowledge. It is possible to see how the multifaceted picture of the use of expert knowledge in regional health authorities is due to the fact that expert knowledge has served the purpose of solving problems to increase output, i.e. in an instrumental fashion, while at the same time validating other claims and thus serving as a source of political legitimacy. While conflict can arise when various actors - medical management and political decision-makers - involve themselves in discussions on the national guidelines that serve to legitimize their different claims, the guidelines can still be used in an instrumental fashion by medical management. 


\section{National guidelines and the risk of reinforcing a silo mentality}

As noted by Matland (1995 p.156), "policy conflict will exist when more than one organization sees a policy as directly relevant to its interests and when the organizations have incongruous views". The risk of conflict in the case of national guidelines is somewhat offset by the non-mandatory character of the guidelines, which moves towards an institutional response characterized by avoidance and compromise. However, the obvious limitation of national guidelines for political use in the context of regional health authorities is at the same time prevalent in decision-making. The goals of the policy, equal and efficient care, and the uncertainty about who, among multiple stakeholders, is responsible for the guidelines within the regional health authority, is a source of ambiguity and potential conflict.

In addition, those who are potentially responsible represent different rationales: a political rationale and a scientific rationale. The dominant scientific rationale of the national guidelines can create instability when pushing for use in explicit priority-setting. Priority-setting in the institutional setting of a regional health authority has strong elements of a wicked problem. In comparison to a tame problem, which only requires a targeted solution, a wicked problem is characterized by high complexity and being persistently hard to solve (Williams et al. 2012). A recurring dilemma is that priority-setting still contains many wicked problems, as social values and political considerations remain important parts of the policy process. Expert knowledge, such as the national guidelines has, as Klein (2003) puts it, "very little to say about the implementability or political acceptability of a policy" (p.430).

A weakness of the national guidelines, as identified in this thesis, is that the guidelines can reinforce a silo mentality in the Swedish health policy arena. In other words, each service area is discussed separately rather than as part of a health care system with multiple interests, where there has to be a coherent framework of services. This could be seen as a significant deficiency in the national guidelines as a policy instrument, especially as they aim to support decision-makers in the regional health policy arena when solving the problem of allocating resources between a large number of interests and needs. The dilemma of prioritization remains, regardless of all the ambitions to apply a "technocratic fix". In political decision-making, expert knowledge is not necessarily a valuable contribution. Evidence can be both a hindrance and an opportunity in the policy-making process, depending on the form in which evidence is presented and at what stage in the policy process. Sometimes the most important contribution to political discussion is not the use of "best" evidence, but rather finding ways to use evidence in decision-making (Glasby et al. 2007). 


\section{The importance of context}

As shown, institutionally shaped responses to the national guidelines could be fragmented and the findings illustrate how more knowledge, whether packaged as scientific evidence or something else, is not the self-evident solution to the difficult challenges encountered in the Swedish health care policy arena. As demonstrated in this thesis, organizations will respond, adjust and react to external pressure according to the conditions shaped by the institutional context. In study 1, which illustrates changes over time, the context is not fixed. As Lin (2003) points out, "Policy is often not a single decision, but a web of decisions that take place and evolve over time. Policy is also often a non-decision, or a process of succession" (p. 5). However, in study 2, the stable components of institutions are also visible, such as the dominant scientific rationale of the national guidelines. Thus, this points to a need to understand both institutional factors and the specific context when introducing expert knowledge.

Likewise, the considerable influence of context makes it difficult to use expert knowledge successfully according to a pre-determined checklist. However, even though the institutionally shaped response can take many forms, it is not impossible to understand. Instead of thinking of the response as fixed, one should consider it as a part of a process, requiring an understanding of the institutional context, adjustments to the actors involved and an ability to make modifications along the way. 



\section{FINAL REMARKS}

The aim of this thesis was to explore the institutionally shaped response to the introduction of the national guidelines in the Swedish regional health policy arena. The results can enhance our understanding of a complex phenomenon and give a deeper understanding of the complexity and challenges connected to the use of expert knowledge, not only in the Swedish health policy arena but also more generally in a decision-making context where different values and interests exist. The studies that constitute this thesis illustrate how the national guidelines create a multifaceted and complex response where different rationalities collide and conflicts appear, and how this is handled within the regional health authorities.

It may be easy to dismiss national guidelines as something that consumes a great deal of resources and is still not used as intended. Given the complexity of the health policy arena, it is however important to have realistic expectations of a policy instrument. Seen from a wide perspective on usability, the national guidelines contribute to dialogue and decision-making.

The most important implication that the findings of this thesis can have for the future of national guidelines in the Swedish health policy arena is the importance of understanding how different rationales can affect how expert knowledge is used. National guidelines as a policy instrument should be further advanced with an understanding of the distinct roles and rationalities that are, and will continue to be, present in the Swedish health care policy arena. It is important that the impact of colliding rationalities is considered in order to sustain the legitimacy of the national guidelines.

In future research, the competing rationales in the health policy arena ought to be further explored to understand the implications of different policy instruments. In the wider perspective of policy-making processes in the health care policy arena, there is also a need for further exploration of the many forms of expert knowledge that are present in decision-making. With a better understanding of the conditions of political decision-making on the health care policy arena, evidence can find its place and be more likely to make a contribution so that more substantiated and solid decisions can be made. 



\section{APPENDIX - QUESTIONNAIRE}

Can you tell me about yourself, i.e. your name, background and role within the regional health authority?

How is your role connected to the national guidelines and the National Guidelines for Cardiac Care?

Have you in some way participated in or been in contact with the development of the National Guidelines for Cardiac Care?

How do you view the national guidelines?

What, in your view, is the goal of the national guidelines?

Who do you consider to be the target group for the national guidelines?

Do you consider it to be clear how the guidelines should be used in practice?

Do you think that the content of the national guidelines is in line with current changes within Swedish health care?

Do you see anything controversial about the national guidelines?

Do you think that the guidelines intrude on or strengthen the autonomy of the regional health authority in any aspect? (question to politicians only)

What role have politicians/administrators/medical professionals had in the implementation of the National Guidelines for Cardiac Care in your regional health authority?

How have the politicians/administrators/medical professionals acted based on the guidelines in your regional health authority?

Has anyone particularly taken the initiative in the implementation process for the National Guidelines for Cardiac Care?

Has there been any change in the regional health authority organization that may have affected the conditions for implementing the National Guidelines for Cardiac Care? (question to administrators only)

What decisions based on the National Guidelines for Cardiac Care can the medical profession take in the regional health authority without the participation of others?

In what contexts are political decisions required?

Do you think that the National Guidelines for Cardiac Care have played any role in initiating or enhancing the dialogue between politicians and/or administrators and/or the medical profession?

Is there any knowledge exchange between medical professionals, administrators and politicians on the basis of the National Guidelines for Cardiac Care? 
Are the national Guidelines for Cardiac Care used in this regional health authority in any way to create consensus on the development and organization of cardiac care?

Why do you think that some people within the medical profession start to act according to the guidelines? Why not? (question to medical profession only)

What do you see as the driving force for medical professionals to act according to the guidelines? What are the major difficulties? (question to medical profession only)

Have you as a politician/administrator/medical professional used the National Guidelines for Cardiac Care as support for decision-making? In what way?

Have you as a politician used the National Guidelines for Cardiac Care to lead and govern in any other way? (question to politicians only)

Have you used the content of the National Guidelines for Cardiac Care in relation to:

Analysis of needs within cardiac care in your regional health authority?

Following up on cardiac care?

Discussions with other groups/within your group in your regional health authority?

Discussions with patient organizations in your regional health authority?

Educational or informational activities (participated/arranged)?

Has the use of National Guidelines for Cardiac Care changed over time?

Has the introduction of the National Guidelines for Cardiac Care been a planned process or more ad hoc?

What has facilitated the introduction of the content of the National Guidelines for Cardiac Care?

What has hampered or prevented the introduction?

Have any political structures been created to deal with the national guidelines/the National Guidelines for Cardiac Care? (question for politicians only)

What besides the National Guidelines for Cardiac Care has affected developments within cardiac care?

Is there anything else that may have had an impact on the conditions for implementation?

Has the content of the National Guidelines for Cardiac Care in some way affected the composition of cardiac care?

Do you think that the National Guidelines for Cardiac Care have in some way provided support for decision-making concerning the allocation of resources within your regional health authority? How? 
How do you think the National Guidelines for Cardiac Care have affected medical professionals as a group in relation to other groups? (question to administrators only)

Can you see any negative effects that have appeared within your regional health authority because of the National Guidelines for Cardiac Care?

How do you think the National Guidelines for Cardiac Care have affected the conditions for running cardiac care in your regional health authority? Is there anything else that you would like to add? 



\section{ACKNOWLEDGEMENTS}

Thank you Peter Garpenby and Bo Persson, for your time and guidance. Thank you Region Östergötland for the initial possibility to do this.

Thank you to my colleagues at The Division of Health Care Analysis, especially Jenny Alwin.

Thank you Fredrik, the love of my life, for your support.

A valuable experience in many ways. 



\section{REFERENCES}

Alvesson, M \& Sköldberg, K (2018) Reflexive Methodology - New Vistas for Qualitative Research. Third edition. London: Sage.

Best, A., Holmed, B. (2010) System thinking, knowledge and action: towards better models and methods. Evidence and policy, 6 (2), 145-159.

Bijker, W.E., Bal, R., Hendrik, R. (2009) The Paradox of Scientific Authority: The Role of Scientific Advice in Democracies. Cambridge, MA: MIT Press.

Black, N. (2001) Evidence based policy: proceed with care. BMJ: British Medical Journal, 323, 275-8.

Blomgren, M. \& Sahlin, K. (2007) Quests for transparency: signs of a new institutional era in the healthcare field. In Christensenand, T. \& Lægreid, P. (eds) Transcending New Public Management. Aldershot: Ashgate.

Bogner, A., Littig, B., Menz, W. (2009) Interviewing Experts. New York, NY: Palgrave Macmillian.

Boyatzis, R. E. (1998) Transforming Qualitative Information: Thematic Analysis and Code Development. London: Sage.

Boswell, C. (2008) The political functions of expert knowledge: knowledge and legitimation in European Union immigration policy. Journal of European Public Policy, 15(4), 471-488.

Boswell, C. (2009) The Political Uses of Expert Knowledge: Immigration Policy and Social Research. Cambridge: Cambridge University Press.

Boyatzis, R. E. (1998) Transforming Qualitative Information: Thematic Analysis and Code Development. London: Sage.

Burau, V., Wilsford, D., France, G. (2009) Reforming medical governance in Europe. What is it about institutions? Health Ecnomics, Policy and Law, 4, 265-281.

Calltorp, J. (1999) Priority setting in health policy in Sweden and a comparison with Norway. Health Policy, 50: 1-22.

Carlsson, P. (2010) Priority setting in health care: Swedish efforts and experiences. Scandinavian Journal of Public Health, 38, 561-4.

Dickinson, H., Freeman, T., Robinson, S., Williams, I. (2011) Resource scarcity and priority-setting: from management to leadership in the rationing of health care? Public Money \& Management, 31(5), 363-370.

Dobrow, MJ., Goel, V., Upshur, R.E.G. (2004) Evidence-based health policy: context and utilisation. Social science \& Medicine 58, 207-217.

Eckard, N., Nedlund, A.C., Janzon, M., Levin, L.Å. (2017) Reaching agreement in uncertain circumstances: the practice of evidence-based policy in the case of the Swedish National guidelines for heart diseases. Evidence \& Policy, 13(4), 687-707. 
Fereday, J. \& Muir-Cochrane, E. (2006) Demonstrating rigor using thematic analysis: a hybrid approach of inductive and deductive coding and theme development. International Journal of Qualitative Methods, 5(1), 1-11.

Ferlie, E., Dopson, S., Fitzgerald, L., Locock, L. (2009) Renewing policy to support evidence-based health care. Public Administration, 87(4), 837-52.

Fernler, K. (2015) Informed ignorance and the difficulty of using guidelines in policy processes. Evidence \& Policy: A Journal of Research, Debate and Practice, 11(3), 377-396.

Flick, U. (2009) An Introduction to Qualitative Research. London: Sage.

Fredriksson, M., Blomqvist, P. and Winblad, U. (2012) Conflict and compliance in Swedish health care governance: soft law in the 'shadow of hierarchy'. Scandinavian Political Studies, 35(1), 48-70.

Fredriksson, M., Blomqvist, P. and Winblad, U. (2014) Recentralizing health care through evidence-based guidelines - striving for national equity in Sweden. BMC Health Services Research, 14, 509.

Freeman, R., Moran, M. (2000) Reforming health care in Europe. Journal West European Politics, 23(2), 35-58.

Garpenby, P, Carlsson, P. (1999) Mot bättre vetande. Statens roll vid kunskapsstyrning av hälso- och sjukvården. In God vård på lika villkor? - underlag till slutbetänkande. Bilaga 2-6. Bilagor till slutbetänkande av Kommittén om hälso- och sjukvårdens finansiering och organisation HSU 200O. SOU 1999:66. Stockholm: Socialdepartementet.

Garpenby, P., Andersson, A., Junker, S.O. (2005) Utvärdering av implementeringen av Nationella riktlinjer för hjärtsjukvård i fyra landsting och regioner. Första delen. Linköping: Prioriteringscentrum Rapport 2005:4.

Garpenby, P., Johansson, P. (2007) Nationella riktlinjer för hjärtsjukvård. Implementeringen i fyra landsting och regioner. Andra delen av utvärderingen. Linköping: Prioriteringscentrum Rapport 2007:5.

George, AL., Bennett, A. (2005) Case Studies and Theory Development in the Social Sciences. Cambridge MA: MIT Press.

Glasby J, Walshe K, Harvey G. (2007) Making evidence fit for purpose in decision making: a case study of the hospital discharge of older people. Evidence and Policy 3(3): 425-437.

Greenhalgh, T. and Russel, J. (2009) Evidence-based policymaking: a critique. Perspectives in Biology and Medicine, 52, 304-18.

Grip, L., Lindahl, B., Levin, L. Å., Kärvinge, C., Eklund, K., Wallentin, L. (2011) From European to National guidelines on heart disease. Scandinavian Cardiovascular Journal, 45(1), 3-13.

Hall, P.A., Taylor, R.C.R. (1996) Political Science and the Three New Institutionalisms. Political Studies, 44(5), 936-957.

Ham, C., Hunter DJ., Robinson, R. (1995) Evidence based policymaking. BMJ: British Medical Journal, 310, 71. 
Ham, C. \& Coulter, A. (2000) Introduction: International experience of rationing (or priority setting), In Ham, C. \& Coulter, A. (eds), The Global Challenges of Health Care Rationing. Buckingham: Open University Press.

Hill, M. \& Hupe, P. (2009) Implementing Public Policy: An Introduction to the Study of Operational Governance (2nd ed.) London: Sage.

Hood, C. (2011) The Blame Game: Spin, Bureaucracy, and Self-Preservation in Government. Princeton: Princeton University Press.

Jewell, CJ., Bero, LA. (2008) Developing Good Taste in Evidence: Facilitators of and Hindrances to Evidence-Informed Health Policymaking in State Government. The Millbank Quarterly. 86(2), 177-208.

Kalkan, A., Sandberg, J., Garpenby, P. (2015) Management by knowledge in practice - implementation of National Healthcare Guidelines in Sweden. Social Policy and Administration, 49(7), 911-927.

Klein, R. (1993) Dimensions of rationing: who should do what? BMJ: British Medical Journal, 307(6899), 309-311.

Klein, R. (2003) Evidence and policy: interpreting the Delphic oracle. Journal of the Royal Society of Medicine, 96, 429-431.

Kuhlmann, E. \& Burau, V. (2008) The healthcare state in transition, national and international contexts of changing professional governance. European Societies, 10(4), 619-633.

Kvale, S. (2009) Den kvalitativa forskningsintervjun. Lund: Studentlitteratur.

Lin, V. (2003) Competing rationalities: evidence-based health policy? In Lin, V., \& Gibson, B. (eds) Evidence-Based Health Policy: Problems and Possibilities. Melbourne: Oxford University Press.

McCaughey, D, Bruning, N.S. (2010) Rationality versus reality: the challenges of evidence-based decision making for health policy makers. Implementation Science 5, 39.

Magnussen, J., Vrangbæk, K., Saltman, R.B. (2009) Nordic health care systems. Recent reforms and current policy challenges. European Observatory on Health Systems and Policies Series. Glasgow: Open University Press

March, J.G., Olsen, J.P. (1996) Institutional Perspectives on Political Institutions. Governance. An international journal of policy, administration, and institutions. 9(3), 247-264.

Matland, R. E. (1995) Synthesizing the implementation literature: the ambiguity conflict model of policy implementation. Journal of Public Administration Research and Theory, 5, 145-74.

Nutley, S.M., Walter, I., Davies, H.T.O (2007) Using Evidence: How research can inform public services. Bristol: The Policy Press

Oliver, C. (1991) Strategic responses to institutional processes. Academy of Management Review, 16, 145-79.

Patton, M. (1990) Qualitative Evaluation and Research Methods. Beverly Hills, CA: Sage. 
Peters, GP. (1999) Institutional theory in political science: the new institutionalism. London, New York: Pinter

Plsek, P. \& Greenhalgh, T. (2001) The challenge of complexity in health care. British Medical Journal, 323, 625-628.

Powell, W.W., DiMaggio, P.J (1991) The New Institutionalism in Organizational Analysis. The United States of America: The University of Chicago Press

Radaelli, C. M. (1995) The role of knowledge in the policy process. Journal of European Public Policy, 2(2), 159-183.

Robinson, S., Williams, I., Dickinson, H., Freeman, T., Rumbold, B. (2012) Priority-setting and rationing in health care: evidence from the English experience. Social Science \& Medicine, 75, 2386-2393.

Saarni, S. I. \& Gylling, H. A. (2004) Evidence based medicine guidelines: a solution to rationing or politics disguised as science? Journal of Medical Ethics, 30(2), 171-175.

Sabatier, P. A. (ed.) (2007) Theories of the Policy Process. Boulder, CO: Westview Press.

Schrefler, L. (2010) The usage of scientific knowledge by independent regulatory agencies. Governance, 23(2), 309-330.

Scott, W.R. (2008) Institutions and Organizations: Ideas and Interests (3rd ed.) Los Angeles, CA: Sage Publications.

Syrett, K. (2003) A technocratic fix to the "legitimacy problem"? The Blair government and health care rationing in the United Kingdom. Journal of Health Politics, Policy and Law, 28(4), 715-746.

Thelen, K. (1999) Historical institutionalism in comparative politics. Annual Review Political Science, 2, 369-404.

Weiss, C. H. (1979) The many meanings of research utilization. Public Administration Review, 39(5), 426-431.

Williams, I., Robinson, S., Dickinson, H. (2012) Rationing in Health Care. The Theory and Practice of Priority Setting. Bristol: Policy Press.

Williams, I. (2015) Receptive rationing: reflections and suggestions for priority setters in health care. Journal of Health Organization and Management, 29(6), 701-710.

Yin, R.K. (2003) Case study research. Design and Methods. (3rd ed.) Applied Social Research Methods Series Volume 5. United States of America: Sage Publications. 


\section{Papers}

The papers associated with this thesis have been removed for copyright reasons. For more details about these see:

http://urn.kb.se/resolve?urn=urn:nbn:se:liu:diva-152648 